\title{
Influence of Processing Parameters on the Magnetic Properties of Mn-Zn Ferrites
}

\author{
S. A. El-Badry \\ ME Lab., Phys. Dept., Faculty of Science, Al-Azhar Univ., Nasr City, Cairo, Egypt.
}

\begin{abstract}
Pure $\mathrm{MnO}_{2}, \mathrm{ZnO}$ and $\mathrm{Fe}_{2} \mathrm{O}_{3}$ were used to prepare a $\mathrm{Mn}$-Zn Ferrite sample of the nominal composition $\mathrm{Mn}_{0.64} \mathrm{Zn}_{0.29} \mathrm{Fe}_{2.07} \mathrm{O}_{4}$. These oxides were mixed firstly for $\mathrm{lhr}$, and then were milled for 20 and for 40 hrs. The as-mixed and the milled powders were examined by XRD and ME spectroscopy. The investigated samples were further mixed with PVA, granulated, cold pressed and sintered at different temperatures (1000, 1300 and $\left.1400^{\circ} \mathrm{C}\right)$ for 2 hrs and were then reinvestigated again. The magnetic properties of all samples before and after sintering were characterized using VSM at a field of $15 \mathrm{k}$ Oe.
\end{abstract}

When the powder oxides were milled for $20 \mathrm{hrs,} \mathrm{detectable} \mathrm{diffusion} \mathrm{reaction} \mathrm{was} \mathrm{observed}$ where the centers of all XRD peaks (due to $\mathrm{Fe}_{2} \mathrm{O}_{3}$ and $\mathrm{MnO}_{2}$ ) shifted to higher $2 \theta$ angles, suggesting that $\mathrm{Zn}^{2+}$ cations had diffused through $\mathrm{Fe}^{3+}$ and/or $\mathrm{Mn}^{4+}$ lattices. The observed increase in the width of the XRD peaks can be attributed to the refinement of the powders by milling. Milling of the powder for 40 hrs resulted in the formation of spinel phase of ( $\mathrm{Zn}$, Fe), but $\mathrm{MnO}_{2}$ was disappeared probably due to the formation of amorphous structure. Sintering at 1000, 1300, and $1400^{\circ} \mathrm{C}$ resulted in the formation of different spinel $(\mathrm{Mn}-\mathrm{Zn})$ ferrites.

The ME measurements followed the gradual formation the manganese zinc ferrite until complete formation which observed in the sample that milled for 40 hrs followed by sintering at $1300^{\circ} \mathrm{C}$ for two hrs. However, it can be concluded that, the processing conditions of such sample represent are the best conditions for obtaining a soft manganese zinc ferrite (single phase).

Key words: Mn-Zn ferrite, Ferrites, Soft magnets, XRD, ME spectroscopy and Magnetic properties.

\section{INTRODUCTION}

Soft magnets are presently the basic elements of many electronic, electrotechnics and mechanical devices. They are used now from the base appliances up to different techniques in the space shuttle. Mn-Zn ferrites represent a group of the most widely used soft magnets in 
many electronic applications, eg. Choke coils, loud speaker, noise filters, recording heads, broad band impulse transformers, etc [1-3]. These materials exhibit excellent properties such as high permeability, high saturation magnetization, high resistivity and low power loss [4]. But in all cases the preparation technique is a matter of interest. The usual solid state reaction (ceramic) method appeared now of low interset since it yields ferrite with comparatively large grain size. Nowadays, powder milling method has been wildly used to prepare small particle size spinel ferrites [5-11].

It was found that, the magnetic properties of $\mathrm{Mn}-\mathrm{Zn}$ ferrite are very sensitive to the processing parameters such as composition, additives, raw materials, attrition milling, and sintering conditions. The change in one or more of these parameters affects widely the magnetic properties of such materials [11-15].

On the other hand, ${ }^{57} \mathrm{Fe} \mathrm{ME}$ spectroscopy has been succesflly applied to investigate the structure of iron compounds including variety of spinel ferrite systems as well as to get interesting information about their hyperfine structure, cation distribution and their internal magnetic properties [16].

Accordingly, this article was devoted to investigate the effect of the milling time as well as the sintering temperature on the magnetic properties of Mn-Zn ferrite applying XRD, ME spectroscopy and VSM techniques.

\section{EXPERIMENTAL}

Pure manganese dioxide, zinc oxide and ferric oxide were used to prepare a $\mathrm{Mn}-\mathrm{Zn}$ ferrite sample of the nominal composition $\mathrm{Zn}_{0.29} \mathrm{Mn}_{0.64} \mathrm{Fe}_{2.07} \mathrm{O}_{4}$. The mean particle size of the used oxides was between $63 \sim 20 \mu \mathrm{m}$. These oxides were mixed together using a double cone mixer until almost complete mixing was obtained (after $1 \mathrm{hr}$ ). The mixed powder was firstly examined by XRD and ME spectral analysis, and was then divided into two parts. The first part was further mixed with $6 \%$ PVA, granulated and then cold pressed at $40 \mathrm{Mpa}$, in a floating die pressing, several compacts of rectangular shape. Some of these compacts were sintered at $1000{ }^{\circ} \mathrm{C}$, some others at $1300{ }^{\circ} \mathrm{C}$, and the rest of the compacts were sintered at $1400{ }^{\circ} \mathrm{C}$ for two hrs. The second part was subjected to mechanical milling using three dimensional hardened steel balls vial containing high chromium steel balls of $6 \mathrm{~mm}$-diameter (spex 8000). The weight ratio between the balls and the charged powder was 10:1. The milling operation was continued for $40 \mathrm{hrs}$, but some of the milled powders for 20 and $40 \mathrm{hrs}$ were mixed with $6 \%$ PVA, granulated, and were cold compacted at $40 \mathrm{Mpa}$. These compacts were further sintered at one of the following temperatures: 1000,1300 or $1400^{\circ} \mathrm{C}$ for two hrs.

Extensive investigation by XRD for different processing condition was performed using Phillips P.W. 1390 diffractometer using Co- $\mathrm{K}_{\alpha}$ radiation and $\mathrm{Mn}$ single-crystal monchromater. Density measurements were also measured using Archimedes principle in toluene liquid. 
A conventional constant acceleration ME spectrometer outfitted with $25 \mathrm{~m} \mathrm{Ci}{ }^{57} \mathrm{Co}$ radioactive source was used to obtain the Mossbauer spectra of the studied samples at room temperature.

The magnetic properties of the powder samples before and after sintering were characterized using VSM up to a field of $15 \mathrm{k}$ Oe.

\section{RESULTS AND DISCUSSION}

\subsection{X-Ray Analysis}

The XRD technique was firstly employed here to investigate the structure of the selected samples (as-mixed powder, after milling for $20 \mathrm{hrs,} \mathrm{after} \mathrm{milling} \mathrm{for} 40 \mathrm{hrs}$ as well as after sintering all samples at 1000,1300 and $1400^{\circ} \mathrm{C}$ for $2 \mathrm{hrs}$ ).

The obtained XRD pattern of the as-mixed powder oxides is shown in (Fig.1 a). The analysis of this pattern indicated that the XRD peaks of $\mathrm{MnO}_{2}, \mathrm{ZnO}$ and $\mathrm{Fe}_{2} \mathrm{O}_{3}$ are all present where they are the basic constituting oxides. When these mixed powder oxides were subjected to milling for $20 \mathrm{hrs}$, it appeared that the centers of all peaks due to $\mathrm{Fe}_{2} \mathrm{O}_{3}$ and $\mathrm{MnO}_{2}$ shifted to higher $2 \theta$ angles, but the centers of all peaks due to $\mathrm{ZnO}$ shifted to lower angles (Fig.1 b). However, it can be supposed that a detectable diffusive reaction occurred. It was suggested also that $\mathrm{Zn}^{2+}$ cations had diffused through the $\mathrm{Fe}^{3+}$ and/or $\mathrm{Mn}^{4+}$ lattices. Also, it was noticed that the line width of the XRD peaks increased when the as mixed powder oxides were milled and their intensity decreased. This broadening may be due mainly to the refinement of the crystallite size and the accumulation of the internal strain in the milled powders [17]. With further milling up to $40 \mathrm{hrs}$ (Fig.1C), the diffusive reaction continued and the centers of $\mathrm{Fe}_{2} \mathrm{O}_{3}$ shifted to higher angles and the broadening of the peaks is also increased and their intensity show great decrease. This was associated with the formation of $(\mathrm{Zn}, \mathrm{Fe})$ spinel phases of the composition $\left(\mathrm{Zn}_{0.664} \mathrm{Fe}_{0.336}\right)\left(\mathrm{Fe}_{1.934} \mathrm{Zn}_{0.66}\right) \mathrm{O}_{4}$, and the $\mathrm{MnO}_{2}$ was completely disappeared. The formation of $(\mathrm{Zn}, \mathrm{Fe})$ spinel is due to the continuation of the diffusive reaction of $\mathrm{Zn}^{2+}$ into $\mathrm{Fe}^{3+}$. The disappearance of the $\mathrm{MnO}_{2}$ could be attributed to the formation of amorphous structure as a result of the accumulation of internal strain.

The as mixed powder oxides as well as those milled for $20 \mathrm{hrs}$ and for $40 \mathrm{hrs}$ were all compacted and sintered for $2 \mathrm{hrs}$. They were then subjected to extensive XRD investigation (as exhibited in the experimental part). The analysis of the obtained XRD patterns of all these compacts that sintered at $1000^{\circ} \mathrm{C}$ for $2 \mathrm{hrs}$ indicated that:

1- The sintered compacts made from the as mixed powder oxides only (before milling) showed the formation of a manganese ferrite phase of the composition [(FeO $\left.)_{1.099}(\mathrm{MnO})_{0.011}\right]$ and a $(\mathrm{Zn}, \mathrm{Fe})$ spinel phase of the composition $\left[\mathrm{Zn}_{0.664} \mathrm{Fe}_{0.336}\right]$ and a $(\mathrm{Zn}, \mathrm{Fe})$ spinel phase of the composition $\left[\mathrm{Zn}_{0.664} \mathrm{Fe}_{0.336}\right)\left(\mathrm{Fe}_{1.934} \mathrm{Zn}_{0.066}\right] \mathrm{O}_{4}$. 
2- Compacts made from the milled powder oxides for either 20 or $40 \mathrm{hrs}$, and sintered at $1000{ }^{\circ} \mathrm{C}$, a $(\mathrm{Zn}, \mathrm{Fe})$ spinel phase in addition to different manganese ferrite compositions were detected in the XRD patterns of these samples. In case of $20 \mathrm{hrs}$ milling, the formed manganese ferrite phase was of the composition $\left[(\mathrm{FeO})_{0.899}(\mathrm{MnO})_{0.101}\right]$, indicating that higher Mn content in the formed ferrite phase was obtained than that made from the as-mixed powder oxides.

3- Increasing milling time to $40 \mathrm{hrs}$, the content of the manganese ferrite phase increased and the detected composition was $\left[(\mathrm{FeO})_{0.798}(\mathrm{MnO})_{0.202}\right]$.

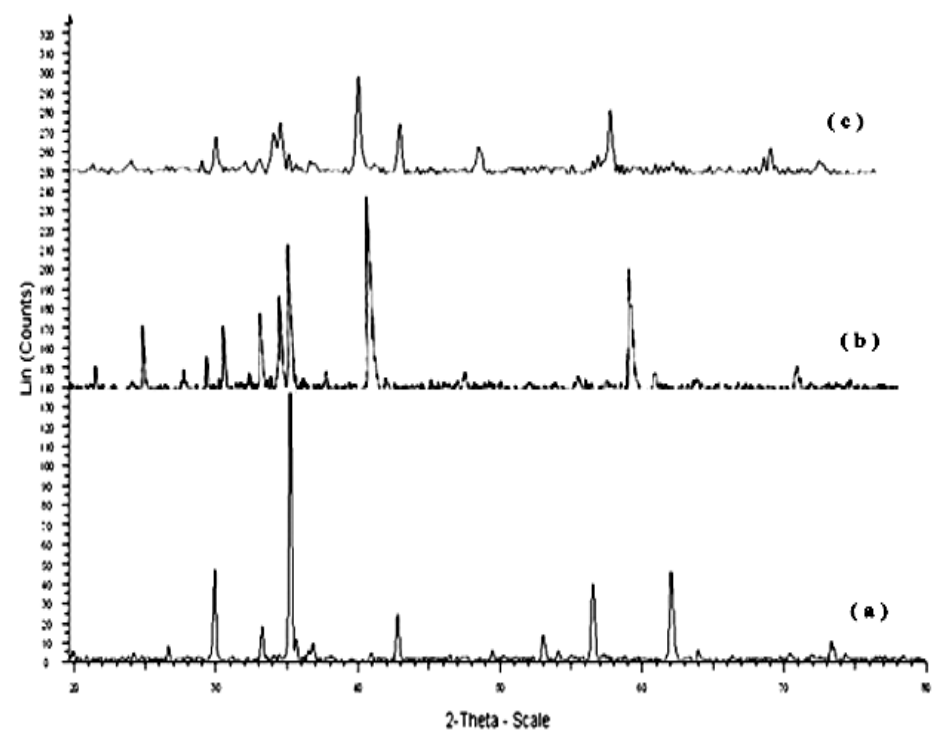

Fig. (1) XRD of:

(a) The as-mixed powder oxides for $1 \mathrm{hr}$.

(b) The as mixed powder oxides for $1 \mathrm{hr}$, milled for $20 \mathrm{hrs}$.

(c) The as mixed powder oxides for $1 \mathrm{hr}$, milled for $40 \mathrm{hrs}$.

Some general features in the obtained XRD results of these samples could be observed, that are:

1- The more milling time is, the more broadening of the XRD peaks.

2- The disappearance of the XRD peaks due to $\mathrm{MnO}$ of the milled powder for $40 \mathrm{hrs}$ at room temperature start to appeared again after sintering at $1000{ }^{\circ} \mathrm{C}$ for only 2 hrs associated with $\mathrm{FeO}$ forming $(\mathrm{Mn}, \mathrm{Fe})$ ferrite phase of the composition $\left[(\mathrm{FeO})_{0.8},(\mathrm{MnO})_{0.2}\right]$.

When the investigated compacts were sintered at 1300 or $1400^{\circ} \mathrm{C}$, a $(\mathrm{Mn}-\mathrm{Zn})$ ferrite phase of the composition $\left[\left(\mathrm{Mn}_{0.64} \mathrm{Fe}_{2.077} \mathrm{Zn}_{0.29}\right) \mathrm{O}_{4}\right]$ was detected for all conditions as shown in (Fig. 2, a - b). The observed differences were shown only in the crystal size and the density. The more milling time is the finer crystal size obtained, but the higher sintering temperature is the more dense material obtained. The sintered material at $1400^{\circ} \mathrm{C}$ has the highest density, but 
with coarser grain size than the other sintered compacts at relatively lower temperatures $\left(1300^{\circ} \mathrm{C}\right)$.

The crystal sizes of the studied ferrite sample in different stages of milling time and sintering temperature, was calculated from the XRD and density measurements. All these results are presented in Table (1).

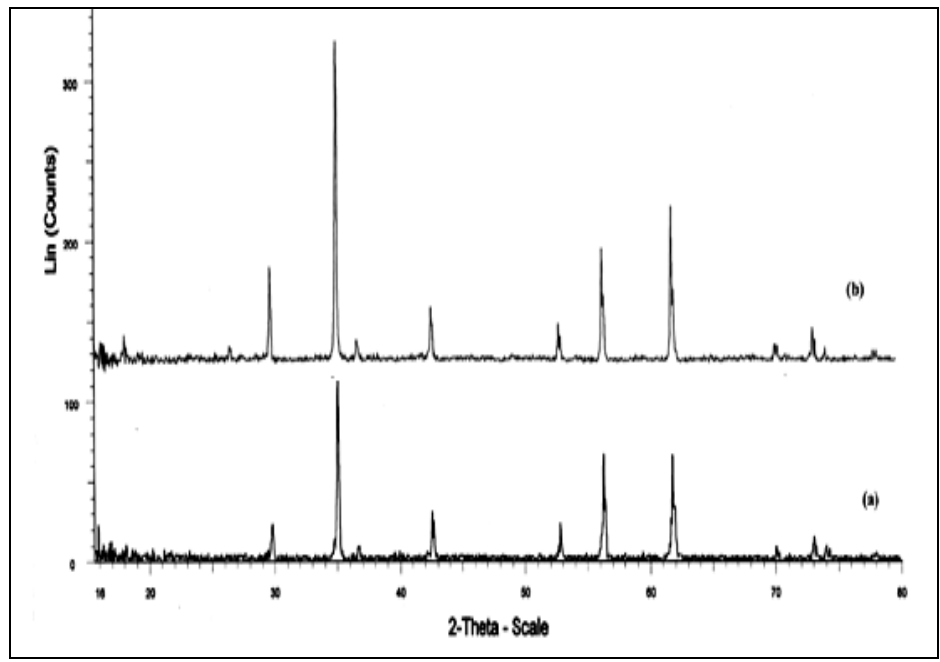

Fig. (2) XRD patterns of the milled compacts for $40 \mathrm{hrs}$ and sintered for $2 \mathrm{hrs}$ at: (a) $1300^{\circ} \mathrm{C}$, (b) $1400{ }^{\circ} \mathrm{C}$.

Table (1). Effect of milling time and sintering temperatures on the crystal size and density measurements of the studied Mn-Zn-ferrites.

\begin{tabular}{|c|c|c|c|}
\hline $\begin{array}{c}\text { Milling time } \\
\mathbf{h r}\end{array}$ & $\begin{array}{c}\text { Sintering temp. } \\
\mathbf{0} \mathbf{C}\end{array}$ & $\begin{array}{c}\text { Crystal size } \\
\mathbf{n m}\end{array}$ & $\begin{array}{c}\text { Density } \\
\mathbf{g} / \mathbf{c}^{\mathbf{3}}\end{array}$ \\
\hline \multirow{4}{*}{ As mixed compacts } & $\mathrm{RT}$ & 202 & 1.65 \\
\cline { 2 - 4 } & 1000 & 215 & 3.2 \\
\cline { 2 - 4 } & 1300 & 225 & 3.83 \\
\hline \multirow{3}{*}{$\mathbf{2 0 h r s ~ m i l l e d ~ c o m p a c t ~}$} & 1400 & 231 & 4.65 \\
\cline { 2 - 4 } & $\mathrm{RT}$ & 96 & 1.03 \\
\cline { 2 - 4 } & 1000 & 101 & 3.15 \\
\cline { 2 - 4 } & 1300 & 160 & 4.3 \\
\hline \multirow{3}{*}{$\mathbf{4 0 h r s ~ m i l l e d ~ c o m p a c t ~}$} & 1400 & 164 & 4.75 \\
\cline { 2 - 4 } & $\mathrm{RT}$ & 45 & 0.83 \\
\cline { 2 - 4 } & 1000 & 90 & 3.11 \\
\cline { 2 - 4 } & 1300 & 106 & 4.2 \\
\cline { 2 - 4 } & 1400 & 120 & 4.75 \\
\hline
\end{tabular}


From Table (1), it is clear that at RT, with increasing milling time the crystal sizes and density decreases as a result of decreasing particle sizes of the used powders. While for mixed compacts, $20 \mathrm{hr}$ milled compacts and $40 \mathrm{hrs}$ compacts with increasing milling time the crystal size decreases and density increases. The increases in the density as the milling time and sintering temperature can be attributed to the decrease of starting milled powder and so increase in the diffusion rate during sintering.

\subsection{Mossbauer Spectroscopy}

It is interesting to apply Mossbauer Effect (ME) spectroscopic analysis to follow the changes due to the processing parameters (milling time and sintering temperature). It can be also applied to study the hyperfine structure of the studied samples as well as to follow Zinc ferrite formation. However, the obtained RT Mossbauer spectra of the studied samples are presented in both Fig. (3) and Fig. (4).

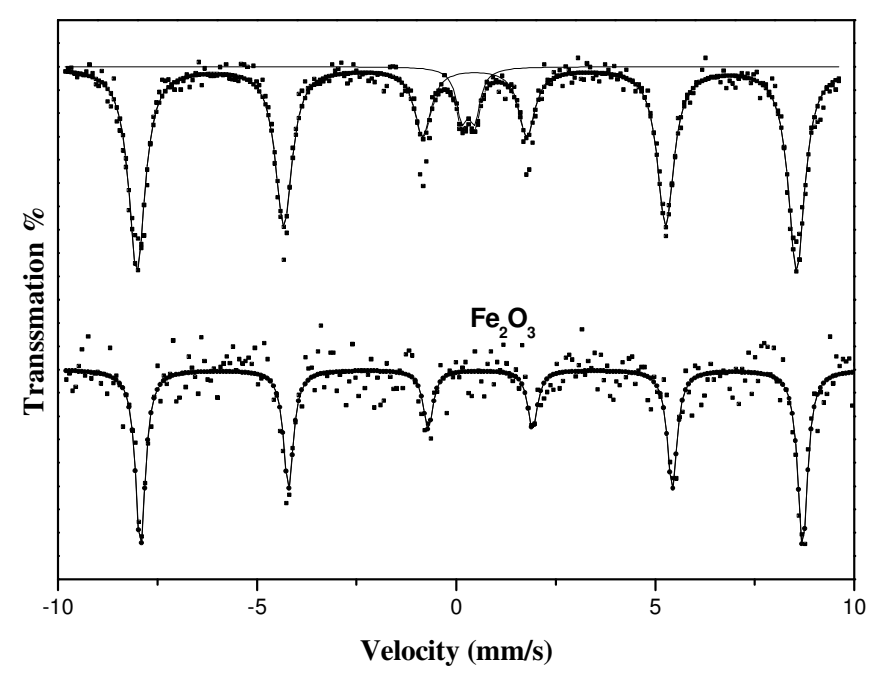

Fig. (3). ME spectra of: The as mixed power oxides for $1 \mathrm{hr}$, and ferric oxide $\left(\mathrm{Fe}_{2} \mathrm{O}_{3}\right)$

Fig.(3) exhibits the ME spectrum of the as mixed powder oxides - only after mixing just for one hour by the double-cone mixer together with the obtained ME spectrum due to pure $\alpha$ $\mathrm{Fe}_{2} \mathrm{O}_{3}$ for comparison. The only observable difference between the two spectra is the appearance of a slight doublet in the spectrum due to the mixed powder oxides. Except this small doublet, both spectra in this figure show typical coincident. In addition, the calculated parameters of the magnetic phase in the spectrum of the as mixed powder oxides and that due to $\alpha-\mathrm{Fe}_{2} \mathrm{O}_{3}$ appeared the same. This can be obviously seen in Table (2). On the other hand, the calculated parameters of the small doublet that appeared in the spectrum of the as mixed powder oxides, are also presented in Table (2). It was found that, for that doublet, the quadruple splitting (QS) energy was $0.318( \pm 0.01) \mathrm{mm} / \mathrm{s}$, while the isomer shift (IS) energy was $0.31( \pm 0.017) \mathrm{mm} / \mathrm{s}$. Also it showed a line width value of $0.338( \pm 0.04) \mathrm{mm} / \mathrm{s}$. This 
indicated that the ferrite formation starts in very little proportions with just mixing for one hour in the double cone-mixer.

Table (2). RT Mossbauer Effect parameters for the measured Mn-Zn ferrite (Some representative samples)

\begin{tabular}{|c|c|c|c|c|c|c|}
\hline Sample & Phase & Qs & Is & Lw & Hf & A\% \\
\hline $\begin{array}{c}\text { As mixed } \\
\text { powder }\end{array}$ & 1 & 0.201 & 0.367 & 0.5 & 514 & 93 \\
\hline & 2 & 0.318 & 0.307 & 0.34 & - & 7 \\
\hline & 1 & 0.041 & 0.279 & 1.085 & 451 & 25.1 \\
Milled for 20 hrs & 2 & 0.0185 & 0.516 & 1.63 & 383 & 63.3 \\
& 3 & 1.79 & 0.526 & 0.658 & - & 11.6 \\
\hline & 1 & 0.241 & 0.371 & 0.613 & 514 & 20.1 \\
Milled for 40 hrs & 2 & 0.799 & 0.428 & 1.73 & 376 & 46.6 \\
& 3 & 1.36 & 0.512 & 1.1 & - & 13.9 \\
\hline $\begin{array}{c}\text { Milled for 40 hr } \\
\text { and sintered at }\end{array}$ & 4 & 0.806 & 1.01 & 0.557 & - & 19.4 \\
$\quad 1300 \mathbf{C}$ & 2 & 0.267 & 0.405 & 0.471 & 508 & 18.8 \\
\hline
\end{tabular}

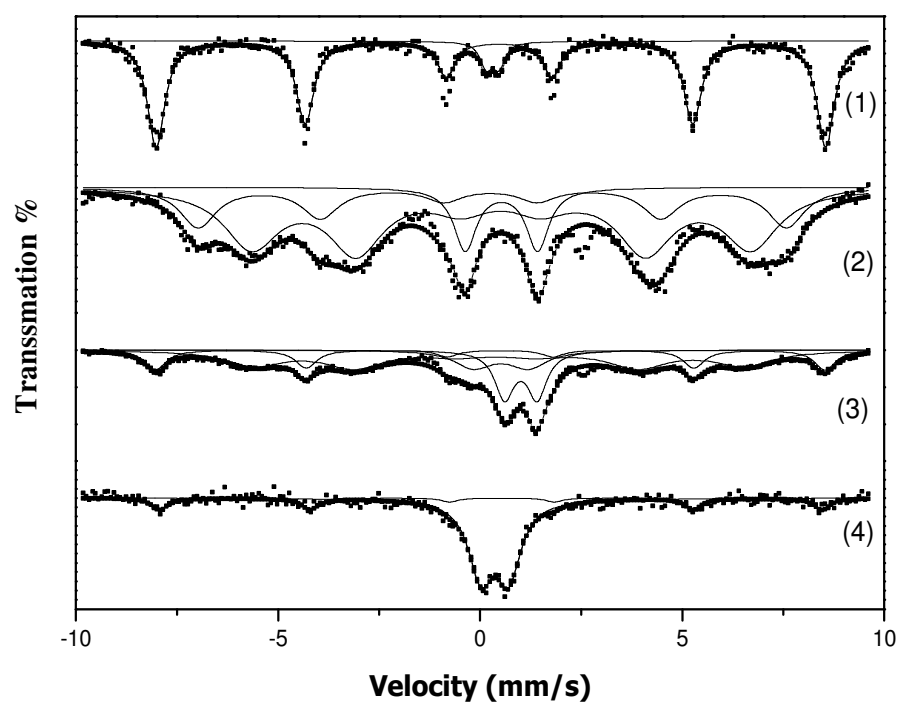

Fig. (4). ME spectra of milled oxides, (1) mixed for $1 \mathrm{hr}$, (2) milling for $20 \mathrm{hrs,} \mathrm{(3)} \mathrm{milling}$ for $40 \mathrm{hrs}$, and (4) after milling for $40 \mathrm{hrs}$ and then calcinations for $1 \mathrm{hr}$ at $1000{ }^{\circ} \mathrm{C}$ and sintering for $2 \mathrm{hrs}$ at $1300{ }^{\circ} \mathrm{C}$.

Fig. (4) exhibits five representative ME spectra, where these spectra are due to:-

1- The ME spectrum of the as mixed powder oxides after mixing by the double-cone mixer for only one hour.

2- The ME spectrum of the mixed powder oxides after milling for $20 \mathrm{hrs}$.

3- The ME spectrum of the mixed powder oxides after milling for $40 \mathrm{hrs}$. 
4- The ME spectrum of the mixed powder oxides after calcinations at $1000{ }^{\circ} \mathrm{C}$ for one $\mathrm{hr}$ and sintering at $1300^{\circ} \mathrm{C}$ for $2 \mathrm{hrs}$.

From these spectra, it is easily to observe the successive decrease of the sub-spectrum due to the ferromagnetic $\alpha-\mathrm{Fe}_{2} \mathrm{O}_{3}$ together with the gradual increase of the paramagnetic (softmagnetic) ferrite material. The computer analysis and fitting of the as mixed powder oxides milled for $20 \mathrm{hrs}$ indicated that, two magnetic iron phases (two sestets) are present. These two sextets may be due to both A and B sites. On going from spectrum (1) to spectrum (5) the ferromagnetic phases decreased gradually until complete disappearance in spectrum (5), while the central paramagnetic doublet increases also gradually, which means the complete formation of a soft magnetic (Mn,Zn) spinal ferrite. The Obtained ME parameters for all the measured samples are also presented in Table (2).

Inspecting the ME spectra 2 and 3, it can be supposed that little relaxation effect appear which may be due to a super-paramagnetic relaxation. This may be in turn due to the effect of milling and the transformation of the particles to the nano-structural size, as concluded from XRD. It can be supposed also that the change of the ferromagnetic to paramagnetic material may be due to the small grain size as well as the disorder introduced by the milling process $[18,19]$. Also, The spectra 1,2 , and 3 show in addition to the central doublets, a complex spectra in which two supper-imposed sextets appeared by fitting corresponding to the tetrahedral A and the octahedral B sites of iron cations.

\subsection{Magnetic Properties}

Fig. (5) shows the magnetization curves for the as mixed powder oxides as well as those milled for 20 and for $40 \mathrm{hrs}$, and all these samples were sintered at $1300^{\circ} \mathrm{C}$,

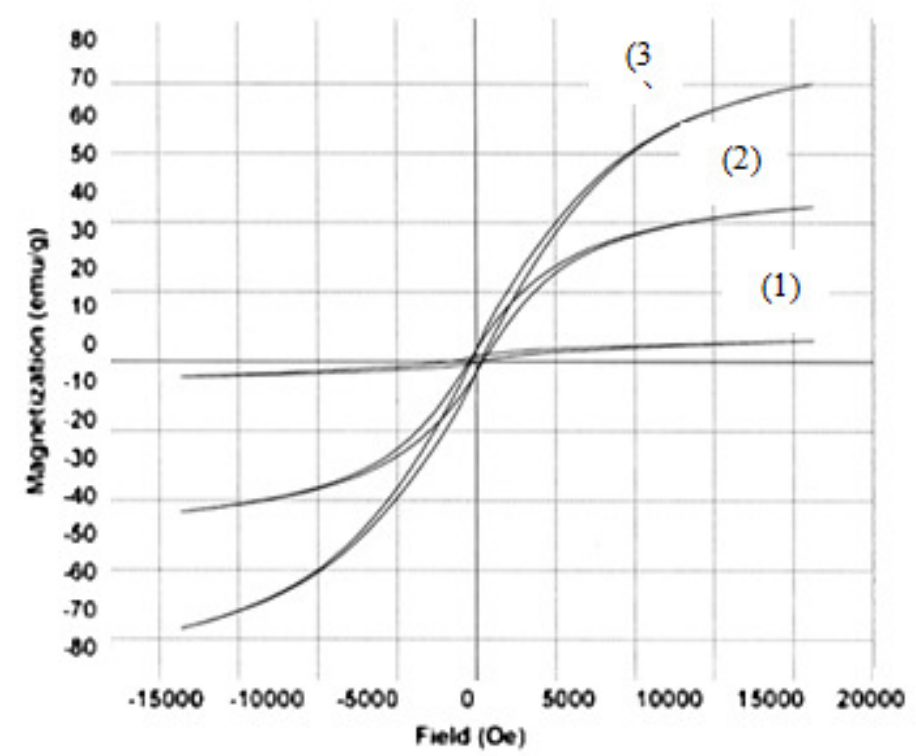

Fig. (5) Some representative hysteresis loops of: (1) The as mixed powder oxides, (2) Milled for $20 \mathrm{hr}$, and (3) Milled for $40 \mathrm{hrs}$. 
Table (3) summarizes the effect of milling time and sintering temperature on the magnetic properties of the investigated materials. From this Table, it could be seen that when the milling time of the as mixed powder oxides was gradually increased (before sintering), the coercive force $(\mathrm{Hc})$ decreased gradually from 234.3 to $75.81 \mathrm{Oe}$. It was observed also that the reminence magnetization $(\mathrm{Br})$ and the saturation magnetization $(\mathrm{Bs})$ increased by about 5 and 8 orders when the compacts were milled for 20 or $40 \mathrm{hrs}$ respectively (see Fig. 6). As the sintering temperature was gradually increased from 1000 up to $1400{ }^{\circ} \mathrm{C}$, a critical drop of the coercive force was obviously seen, while the reminence and the saturation magnetization showed sharp increase. It is worth to note that, all the values of the measured parameters ( $\mathrm{Hc}, \mathrm{Br}$ and $\mathrm{Bs}$ ) of the sintered compacts at 1300 or $1400{ }^{\circ} \mathrm{C}$ showed approximately similar magnetic behavior.

The observed changes in the magnetic properties of the studied materials could be attributed to both the reduction in the grain size and the formation of spinel ( $\mathrm{Zn}-\mathrm{Fe}$ ) ferrite. It was concluded that the measured parameters of the compact sintered at $1400{ }^{\circ} \mathrm{C}$ exhibited superior magnetic properties than all other sintered compacts which may be due to its highest density value (due to the highest sintering temperature). But, it was easy to observe that the compacts sintered at $1300{ }^{\circ} \mathrm{C}$ have almost the same magnetic properties of that sintered at $1400{ }^{\circ} \mathrm{C}$, but the former have finer grain sizes than the later compact that have coarser grain size. In addition to this the difference between the density values of both these compacts was small and they appeared to be close to each other. However, it could be concluded that the best sample is that milled for $40 \mathrm{hrs}$ and sintered at $1300{ }^{\circ} \mathrm{C}$ for $2 \mathrm{hrs}$. Such processing conditions could form the same ferrite phase with finer average grain size and could produce approximately similar magnetic properties to that sintered at $1400{ }^{\circ} \mathrm{C}$. In addition much thermal energy could be consumed when compared with the compact sintered at $1400^{\circ} \mathrm{C}$.

Table (3) Effect of milling time and sintering temperatures on the magnetic properties of the studied Mn-Zn-ferrites during different stage of processing.

\begin{tabular}{|c|c|c|c|c|}
\hline $\begin{array}{c}\text { Milling time, } \\
\text { hr }\end{array}$ & $\begin{array}{c}\text { Sintering } \\
\text { temp. } \mathbf{\circ}^{\circ}\end{array}$ & $\begin{array}{c}\text { Hc, } \\
\text { Oe }\end{array}$ & $\begin{array}{c}\text { Br, } \\
\text { emu/g }\end{array}$ & $\begin{array}{c}\text { Bs, } \\
\text { emu/g }\end{array}$ \\
\hline & R.T. & 234.4 & 0.030 & 0.24 \\
As mixed compacts & 1000 & 70.04 & 0.191 & 6.23 \\
& 1300 & 11.33 & 0.203 & 18.6 \\
& 1400 & 9.76 & 0.246 & 19.3 \\
& R.T. & 108.8 & 0.142 & 1.98 \\
\hline 20hr milled compact & 1000 & 55.84 & 0.275 & 8.188 \\
& 1300 & 9.14 & 0.344 & 21.72 \\
& 1400 & 8.40 & 0.365 & 22.46 \\
& R.T. & 75.81 & 0.186 & 3.531 \\
\hline 40hr milled compact & 1000 & 51.09 & 0.333 & 12.641 \\
& 1300 & 6.035 & 0.434 & 23.7 \\
& 1400 & 5.033 & 0.479 & 24.61 \\
\hline
\end{tabular}



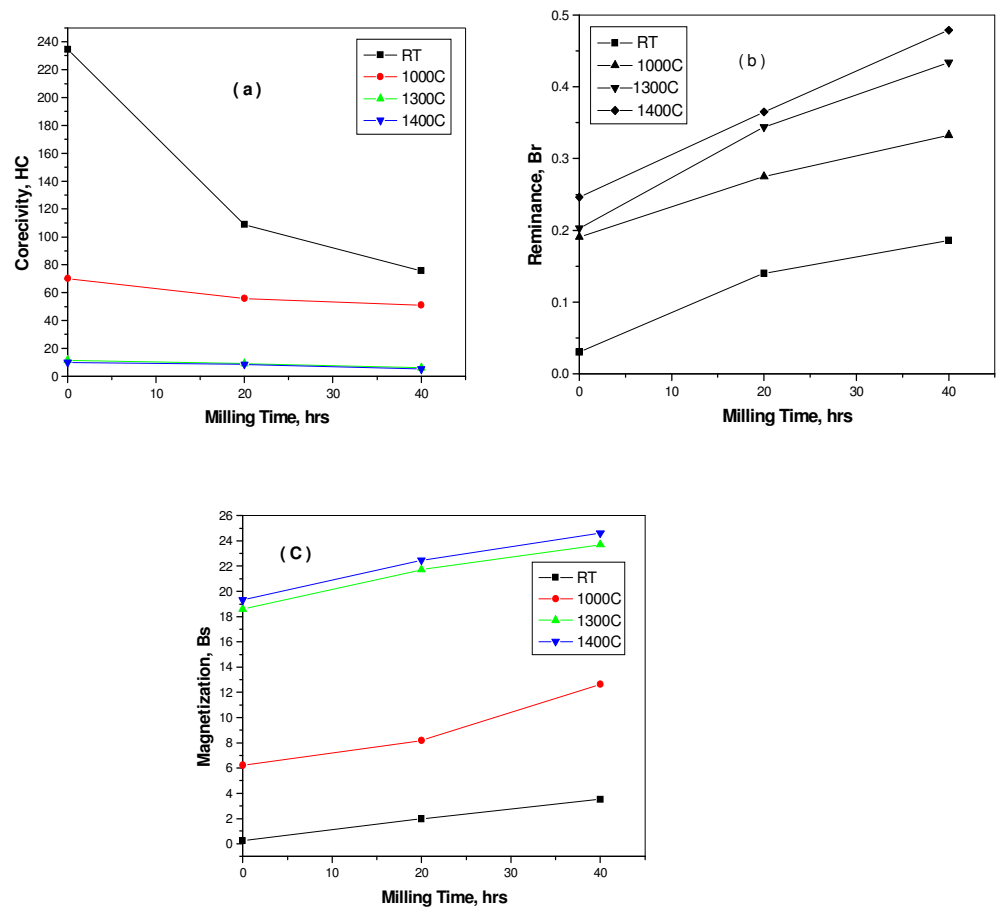

Fig. (6) Effect of milling time and sintering temperature on the magnetic properties of the studied Mn-Zn-ferrites during different stages of processing.

\section{CONCLUSION}

The obtained results demonstrate that the process consisting of both mechanical milling before sintering and then sintering at high temperature is useful for obtaining Mn-Zn ferrite of homogenous structure with fine size distribution which exhibit superior magnetic properties Inspecting the obtained results, it could be concluded that mixing the starting oxides for only one hour was enough to start the ferrite phase formation, as detected by ME spectroscopy. When the milling time was increased, this acted to decrease the particle size, resulting in a nano-particles structure. As the sintering temperature was increased, the density of the studied sample increased and the particle size became coarser, as well as the measured magnetic parameters became also better. Also, it could be seen that the magnetic parameters of the samples milled for $40 \mathrm{hrs}$ and sintered at $1300^{\circ} \mathrm{C}$ and $1400^{\circ} \mathrm{C}$ respectively appeared to be close to each other. Therefore it could be concluded that the best processing conditions were the milling for $40 \mathrm{hrs}$ followed by the sintering at $1300{ }^{\circ} \mathrm{C}$ for $2 \mathrm{hrs}$.

\section{REFERENCES}

1. D. J. Fatemi, V. G. Harris, M. X. Chen, S. K. Malik, W. B. Yelon, . J. Long and A. Mohan, J. Appl. Phys., P. 5172, (1999).

2. J. S. Jiang, L. Gao, X. L. Yang, J. K. Guo and H. L. Shen, J. Mater. Sci. Lett. 18, P. 6867 (1999) 
3. D. J. Fatemi, V. G. Harris,V. M. Browining and J. P. Kirkland, J. Appl. Phys. 83, p. 6867, (1998)

4. S. J. Shukla, K. M. Jadhav. And G.K. Bichile, J. Pure Phys. 39, P. 226 (2001).

5. A. Thakur and M. Singh, Ceram. Int. 29, P. 505 (2003).

6. A. Verma, T. C. Goel, R. G. Mendiratta, in : Second International Conference on processing Materials for properties, The Mineral, Metal \& material Society, P. 493 (2000).

7. A. Thakur, P. Mathur and M. Singh, J. of Phy. and Chem. Of Solids, (2006).

8. A. L. Greer, Phil. Mag. B 61, P. 525 (1990).

9. G. Jain, B. Das, and S.Kumari, IEEE Magn., 16(6), P.1428 (1980).

10. T. Otsuka, E. Otsuki, and T. Sato, ICF6 (6 $6^{\text {th }}$ Inter. Ceramic Conf.), P.317 (1992).

11. J. Fan, and F. Sale, IEEE Trans. Magn., 32(5), P. 4854 (1996).

12. H. J. Fecht, Nanostruct Mater. 1, P. 125 (1992).

13. H. Gleiter, Nanostruct Mater. 6, P. 3 (1995).

14. C. Suryanarayana, Prog., Mater. Sci. 46, P.184, (2001).

15. I. Lin, R. Mishra, and G. Thoma, IEEE Trans. Magn. 22(3), P. 175 (1986).

16. S. M. Attia, Egypt. J. Solids, 29, No.2, P. 329 (2006).

17. C. Linu, J. Wu, C. Chen, and M. Tung, J. magn. Magn. Mater., 133, P.478(1994).

18. J. Xu, J. He and E. Ma, Metall and Mater. Trans., 28A, P, 1969 (1997).

19. R. A. Dunlap, A. Alghamdi, J. W. O`Brien and S. J. Penney, J. Alloys and Compounds, Vol. 365, Issues 1-2, P.84 (2004). 